\title{
An Editorial for Nanoscience and Nanotechnology: An Outlook to Nanotechnology
}

\author{
Mustafa Yavuz*, M. Irannejad, A. Brzezinski, B. Cui, and E. Abdel- \\ Rahman
}

Waterloo Institute for Nanotechnology, University of Waterloo, Canada

Received: December 07, 2013; Accepted: December 19, 2013; Published: December 20, 2013

"Corresponding author: Mustafa Yavuz, Waterloo Institute for Nanotechnology, University of Waterloo, Canada, Tel: 519-888-4567; Fax: 519-885-

5862; E-mail: myavuz@uwaterloo.ca

The idea of synthesis of materials via direct manipulation of atoms, which was called Nanotechnology by Norio Taniguchi in 1974, dates back to renowned physicist Richard Feynman's famous talk in 1959; "There is Plenty of Room at the Bottom". Nanotechnology or Nanotech refers to manipulation of materials on the atomic and molecular level with at least one dimension in the scale of 1 to 100 nanometers. This means that quantum mechanical effects are more important than classical, average, effects. Nanotechnology has variety of potential applications including military, industrial, engineering, medical science and healthcare which resulted in huge investments by governments worldwide in related research programs. Based on definition by National Nanotechnology Initiative in the USA, Nanoscience and nanotechnology are naturally very broad and include many field of science, as diverse as surface science, chemistry, molecular biology, physics, micro fabrication, etc. For example, in the field of physics it includes approaches to device fabrication based on molecular self-assembly, from developing new materials with nanometer scale dimensions to control of matter on the atomic scale. Early in this century, increased scientific, political and commercial attention to Nanotechnology led to both controversy and vital research projects with a variety applications from military to medicine and healthcare [1].

The current research areas in Nanomaterials can be categorized a stop-down and bottom-up approaches, functional and biomimetic approaches and Speculative [2-5]. The field of nanomaterials includes development and study of materials which having unique properties arising from their nanometer dimensions. Interface science has given rise to many materials which is used in nanotechnology such as 2D carbon sheets (graphene), carbon nanotubes, nanorods and various types of nanoparticles. Recently there has been a huge progress in using these types of materials for medical applications such as nanobio-technology, drug delivery and cell repair machines [6-8].

Nanomaterials, such as nanoparticles and nanopillars, could be used in solar cells to reduce the costs of traditional silicon based solar cells. Development of applications incorporating nanoparticles is ongoing, such as quantum dots deployed as semiconductor materials to be used in next generation electronic and photonics products including display technology, solar cells, lighting devices, biological images and biosensors [9].

Molecular nanotechnology is another field which involves manipulating single molecules in precise, controlled and deterministic ways. This field is more theoretical than other fields, and many of its proposed techniques are beyond current technological capabilities.

Some of the more theoretical fields include:

1. Nanorobotics: self-sufficient machines of some functionality operating at the nanoscale. Progress in innovative materials and methodologies has demonstrated and generated patents on nano-manufacturing devices for future commercial application which helps in use of implanted nano-bio-electronics concepts [10-12].

2. Productive nano-systems: systems creating automatically other parts of nano-systems with high accuracy, with using novel nanoscale-emergent properties, and understood as fundamentals of manufacturing processes [13].

3. Programmable materials: materials whose properties can easily be controlled reversibly and externally by nano-engineers.

Increasing demand on nanotechnology since 1959 has led to several important modern developments in industry, such as the atomic force microscope (AFM) with high resolution up to $1 \mathrm{~nm}$, the scanning electron microscope (SEM), the scanning tunneling microscope (STM) with high resolution up to 0.01 $\mathrm{nm}[14,15]$. Moreover, some early versions of these devices have been modified and upgraded along with advancement of nanotechnology, resulting in contemporary "super-tech" nanotools such as optical (laser, UV and deep UV) lithography, x-ray lithography, dip pan nanolithography, electron beam lithography, nanoimprint lithography, focused ion beam milling, atomic layer deposition, molecular vapour deposition and molecular beam epitaxy [16-19]. All these devices have increased precision and 
accuracy in manufacturing at nanoscale, which has tremendous effects on performance of nano and micro devices.

\section{References}

1. Drexler, K. E. (1986). Engines of Creation: The Coming Era of Nanotechnology. New York: Doubleday.

2. Narayan, R. J., Kumta, P. N., Sfeir, Ch., Lee, D-H., Choi, D., \& Olton, D. (2004). Nanostructured ceramics in medical devices: applications and prospects. JOM, 56(10), 38-43.

3. Levins, C. G., \& Schafmeister, C. E. (2005). The synthesis of curved and linear structures from a minimal set of monomers. The Journal of Organic Chemistry, 70(22), 9002-9008.

4. Das, S., Gates, A. J., Abdu, H. A., Rose, G. S., Picconatto, C. A., \& Ellenbogen, J. C. (2007). Designs for ultra-tiny, special-purpose nanoelectronic circuits. IEEE Transactions on Circuits and Systems I, 54(11), 25282540 .

5. Mashaghi, S., Jadidi, T., Koenderink, G., \& Mashaghi. A. (2013). Lipid nanotechnology. International Journal of Molecular Sciences, 14(2), 4242-4282.

6. Boisseau, P., \& Loubaton, B. (2011). Nanomedicine, nanotechnology in medicine. Comptes Rendus Physique, 12(7), 620-636.

7. http://www.nanospectra.com/clinicians/spublications.html.

8. Mozafari, M.R. (Ed). (2006). Nanocarrier Technologies: Frontiers of Nanotherapy. Springer.
9. http://www.photonicsonline.com/doc/wireless-nanocrystalsefficiently-radiate-vis-0002

10. Ghalanbor, Z., Marashi, S. A., \& Ranjbar B. (2005). Nanotechnology helps medicine: nanoscale swimmers and their future applications. Med Hypotheses, 65(1), 198-199.

11. Kubik, T., Bogunia-Kubik, K., \& Sugisaka, M. (2005). Nanotechnology on duty in medical applications. Curr Pharm Biotechnol, 6(1), 17-33.

12. Cavalcanti, A., Shirinzadeh, B., Freitas, R. A. Jr., \& Kretly, L. C. (2007). Medical nanorobot architecture based on nanobioelectronics. Recent Patents on Nanotechnology, 1(1), 1-10.

13.http://www.nsf.gov/crssprgm/nano/reports/mcr_05-0526_ intpersp_nano.pdf

14. Binnig, G., \& Rohrer, H. (1986). Scanning tunneling microscopy. IBM Journal of Research and Development, 30(4), 355.

15. Bai, C. (2000). Scanning tunneling microscopy and its application. New York: Springer Verlag

16. Cho, A. Y., \& Arthur, J. R. (1975). Molecular Beam Epitaxy. Prog. Solid State Chemistry, vol. 10, pp. 157-192

17. Jaeger, R. C. (2002). Lithography, Introduction to Microelectronic Fabrication (2nd ed.). New Jersey: Prentice Hal.

18. McCord, M. A., \& M. J. Rooks. (2000). SPIE handbook ofmicrolithography, micromachining and microfabrication.

19. Chou, S. Y., Krauss, P.R., \& Renstrom, P. J. (1996). Imprint lithography with 25-nanometer resolution. Science, 272(5258), 85-87. 